\title{
Use of Pornography with Sex Offenders in Treatment: A Controversial Conundrum
}

\section{Scott Allen Johnson}

Licensed Psychologist, Forensic Consultation, Minneapolis, USA

"Corresponding author: Scott Allen Johnson, Licensed Psychologist, Forensic Consultation, Minneapolis, USA, Tel: 612 269 3628 ; E-mail: scott@forensicconsultation.org

Rec date: August 29, 2015 Acc date: September 26, 2015 Pub date: September 30, 2015

Copyright: (C) 2015 Johnson SA. This is an open-access article distributed under the terms of the Creative Commons Attribution License, which permits unrestricted use, distribution, and reproduction in any medium, provided the original author and source are credited.

\begin{abstract}
I write this article and literature review to address the issue of incorporating pornography into sex offender treatment programs. I was asked the above question by a handful of probation who supervise sexual offenders and the treatment providers indicated that they would be utilizing pornography as part of sex offender treatment. This creates a problem in that for the sexual offender on probation or parole, they may have court ordered restrictions prohibiting use or possession of any type of pornographic material.

My dilemma is that I find there is no research support for utilizing pornography in any type of treatment for violent and/or sexually violent offenders. The literature is rich, however, with information about the negative impact of pornography for the violent and sexually violent offender. Remember that the violent and sexually violent offender (including some child pornography users), present with significant risk factors and psychological factors that forever place them at risk for violent and/or sexually violent re-offense. Most risk factors are static, that is, they do not go away with treatment or age. For example, having a history of violent or sexually violent behavior will never change, age when the first offense occurred and/or a history of family problems, attachment or intimacy problems or a current or more serious psychological problems do not go away either. To utilize pornography with offenders presenting with such risk factors does not appear supported by the literature and raises concerns for offenders to resume or continue to engage in deviant fantasies via pornography use that may well lead to a violent or sexual reoffense.
\end{abstract}

Keywords: Pornography; Violence; Masturbation; Rape; Childhood; Sex offender

\section{Review of the Literature}

The average pornography user is not likely negatively impacted by the pornographic material they view. In fact out of the approximately millions that use pornography at some point in their lives, only a fraction appear to be negatively impacted in their relationships or choose to engage in violent behavior following their pornography use. If this were not the case, then we would see a significant increase in the number of people seeking relationship/marital counselling or therapy and would definitely see a dramatic increase in violence related offenses.

The term "deviant" and "extreme" will refer to any pornography depicting or including any contact of the following (though not an inclusive list): age-inappropriate (e.g., child molestation), violence, harming, degrading, non-consenting, rape, sexual assault, murder, physical assault, and sadism. Pornography will refer to pictures, images, or videos/movies depicting nudity or persons engaged in any type of sexual contact or behavior. Soft-core refers to people posing with/without clothing or in states of disrobing. Hard-core pornography may be defined as depicting sex acts occurring, whether solitary (masturbation) or with others. The new term being used is sexually explicit material. However, given that the majority of research reviewed utilized the term "pornography", I will use that term to include sexually explicit material. Some of the research did not clearly identify or define the term "pornography" or "deviant", and this raises problems when interpreting data as well as when comparing research data from one article with other.

I also want to acknowledge that there are therapists and programs that utilize pornography for non-offender based issues (e.g., sexual dysfunction, intimacy, couples communication). However, the clients engaged in those therapies are not identified as sexual offenders or even violent offenders to the best of my knowledge. As the literature is discussed in the paper, it will become clear that there exist some disagreement about the impact of pornographic material for the violent offender (sexual and nonsexual). It appears that those offenders who present with predispositions for violence and other issues are at higher risk for having negative outcomes from pornography use than for those offenders who do not. For some offenders, for example, the child pornography user, many may not progress to actual contact offenses. Long-term follow-up is warranted to determine which child porn users eventually become contact offenders.

Literature reviews time and time again have shown that pornography use is linked to violent behavior, including sexually violent behavior [1-12]. In fact, even soft-core pornography use resulted in sex offender's choice to engage in sexual aggression [13].

Malamuth et al., revealed in their meta-analysis that current heavy pornography use was found to be related to sexually aggressive behavior (p. 48) [9]. They also found that in their review that soft-core pornography is positively related to engaging in coercive verbal behavior and the hypothetical likelihood of utilizing sexual force, but 
negatively related to actually using physical force in sex [14]. Further, their review demonstrated that use of violent and rape pornography was positively correlated with sexual coercion, and cautioned that it would be erroneous to conclude that soft-core pornography use was negatively correlated to the likelihood of rape or actual rape behavior. Boeringer found that all types of pornography correlated significantly with the use of verbal coercion and the use of alcohol and/or drugs and that pornography, especially violent pornography (except soft-core) correlated significantly with rape [14].

Crossman found that pornography use was the strongest correlate of sexual aggression and that the more frequently men used pornography and the more violent the pornography they used, the more likely they were to engage in coercive or physically forced sex [5]. Heavy current users of pornography were approximately three times more likely to be sexually aggressive than those who used pornography less frequently [15]. In their meta-analysis of pornography and rape literature, Malamuth et al., concluded that there is a significant association between habitual pornography use and attraction to sexually aggressive/harassing behaviours [9]. They also found that rapists were more aroused by violent pornography but that both nonviolent and violent pornography resulted in a greater likelihood for some form of sexual act for rapists (e.g., masturbation, consensual sex, or rape). Again, those who utilize nonviolent or soft-core pornography frequently are at higher risk for engaging in some form of sexual or nonsexual aggression. Heavy users of pornography may be more sensation-seeking than those who use it less frequently and this may suggest compulsive characteristics that may lead to acting-out the actual behavior depicted in the pornography [16].

Marshall found that most groups of sexual offenders used pornography more than non-offenders [11]. However, this research, though significant, was before internet pornography was available. Today's trend is likely to show that more non-offenders utilize pornography than offenders. Marshall also found that a substantial number of rapists utilized consenting sex depictions to illicit rape images/scenarios in preparing for the actual rape committed. In short, rapists utilized both soft and hard core pornography for stimulating rape thoughts and behavior. This was also supported by Malamuth and MacIlwraith $[17,18]$. It has also been found that viewing pornography involving nudity only reduced sexual aggression whereas exposure to nonviolent and/or violent pornography increased aggression [1,2]. Allen et al. also found that offenders were more likely to act-out after pornography use (masturbation, consensual sex, or forced sex) and that offenders were less aroused by consenting sex and more aroused by violent pornography than non-offenders [1]. For men with higher degrees of psychopathy/high anti-social behavior the association between pornography use and aggression and deviant behavior was very high [19-21]. It was also found that men who are high on risk factors for sexual aggression and who frequently use pornography were at higher risk for engaging in sexual and nonsexual aggression [7,22-24].

Child pornography use may increase the likelihood of child pornography users crossing the line to committing contact sexual offenses. Some of the factors for cross-over into contact sex offenses include the child pornography user experiencing a feeling of wanting to imitate what they have viewed, the belief that the sexual contact with a child is normal or not injurious to the child depicted (e.g., often the child is smiling), and experiencing a sense of reinforcement for sexual feelings towards children as depicted by the pornography [24]. Researchers have found that over half of child pornography users admitted to having one or more contact victims that they had yet to be caught for (undetected offenders) [24,25].

Some child molesters (over $80 \%$ in one study) engaged in child sexual molestation before they possessed child pornography. Child pornography offenders appear to be a heterogeneous group, that is, they do not share many of the same/similar factors, traits, behavior [17]. McCarthy found that those child pornography users that crossed into contact offenses had dispositional factors related to substance abuse, antisocial orientation (including prior sex related arrests), and deviant sexual interests (including the diagnosis of Pedophilia). They also found that child pornography users, who crossed into contact offenses utilized the internet to locate, contact, and groom victims as well as utilized the internet to talk with other sexual offenders. The size of the pornography collection is significant to the amount of time an offender puts into collecting it, as well as time spend organizing the pornography into categories, and contact offenders tend to have much larger collections - however, caution should be used in that the research does not necessarily support that larger collections automatically mean that the offender is at higher risk for contact offenses. McCarthy also found that contact offenders collected both pornographic and non-pornographic material depicting both children and adults and that all of this material should be viewed as significant concerning the offender's risk [17].

No doubt that for some (and at least half according to some studies) viewing child pornography may not ever lead to acting-out with a contact sex offense against a child [26,27]. However, the production of any child pornography is victimizing to the children involved, so it is never a victimless crime! Some may find relief in viewing and masturbating to child pornography as a way to escape other negative feelings or situations, but chose not to engage in touch offenses [28-31]. While for others, they may use child pornography before, during or following a contact child sex abuse situation [28-32].

For child pornography users and sexual offenders against children, there are other specific issues identified that suggest more significant pathology of the offender. Significant attachment deficits, impaired or absent empathy, socio-affective deficits, sexual preoccupation, impaired problem solving, deviant sexual preferences, are only a few of the identified issues [31-34]. In treatment the offender may address some degree of their deficits and issues related to the risk for reoffense, however it is not likely that they will have adequately eliminated all risk related factors (deviant fantasy and/or deviant memories of prior offenses or of deviant sexual interests; relationship and intimacy deficits, problem solving skills, and of course, psychopathy - for which there is no known treatment). Therefore, a necessary caution appears warranted in that the sex offender probably should not utilize pornography as it may reignite deviant fantasies and any pornography use would be extremely difficult to monitor unless utilizing the polygraph - though even the polygraph is not $100 \%$ accurate.

Some researchers opine that there is no negative effect of pornography (more so for soft-core pornography) on sexual offender's fantasy or in their choice to commit sexual or violent offenses or that the effects are nominal [35]. However the literature offers well designed and implemented research articles demonstrating that there is in fact a negative effect of pornography for the sexual and violent offender, for the offender presenting with negative predispositions already mentioned [9]. 


\section{Individual Differences and a Pathway Model in Sex Offending}

There have been several factors that have been suggested to increase the likelihood of violent behavior following pornography use. Selfreported sexual attraction to sexual aggression, hostile masculinity, and/or low intelligence appear to place users of pornography at higher risk for being significantly negatively impacted by the theme/s of the pornography [36-39]. Malamuth, Adison, and Koss indicated that the results of the research on the impact of pornography and personality, for example, is bidirectional, that is, the men who are at higher risk for sexual aggression are more likely to be attracted to and aroused by sexually violent media [9]. They liken this to Bandura's concept of "reciprocal determinism" - "a continuous reciprocal interaction between personal, behavior, and environmental determinants (p. 194) [40]. The offender's social relationships as well as the content of the pornography they chose to use impacts the offender's choice to view/not view pornography as well as what type of pornography they view.

Individual differences accounting for sexual aggression and violence towards women have been narrowed down to two primary factors: life history and current personality characteristics [9]. This included life histories involving growing-up in a home with parental violence and/or child abuse, which was associated with a higher occurrence of juvenile delinquency, which in turn became a strong predictor of greater sexual promiscuity. The paths identified by Malamuth et al. included the Sexual Promiscuity path and the Hostile Masculinity path - if the later was present, there was an increased risk for coercion against women; if both were present in an individual there was a significant likelihood for both sexual and nonsexual aggression towards women [41]. Nonsexual aggression towards women was primarily related to high scores on only the Hostile Masculinity path. The Confluence Model of sexual aggression suggests that sexual aggression is the cumulative result of the interacting factors of Sexual Promiscuity and Hostile Masculinity [42,43]. Now I am only summarizing the above theory and I encourage the reader to read the above author's work to gain a more in-depth understanding.

In their on-going work and more recent meta-analysis, Malamuth, Hald, and Koss found further support for the Confluence Model of sexual aggression and the two paths identified above, Sexual Promiscuity and Hostile Masculinity as being strongly related to sexual and non-sexual aggression towards women [10]. They also found that pornography use also interacted with the above two factors to play a role in sexual and nonsexual violence against women (although unable to identify the directionality of impact - does pornography contribute to aggression towards women or does aggressiveness towards women cause an interest in pornography - either way a connection). Regardless, pornography also played a role. Those men who were already at high risk for engaging in sexual and nonsexual violence and who demonstrated high scores in regards to Sexual Promiscuity and Hostile Masculinity were found to be the highest risk for sexual and nonsexual aggression towards women. Those with higher scores on Sexual Promiscuity and Hostile Masculinity and who are also frequent users of pornography had higher levels of sexual aggression even over those who were high on Sexual Promiscuity and Hostile Masculinity but used pornography less frequent. The bottom line is that there is a connection between frequency of pornography use and the combination of personality factors related to higher degrees of risk for engaging in violent sexual and nonsexual aggression.
And how different people seek out specific types of pornography and how they are impacted by it is likely impacted by predispositions and their on-going social relationships. Based on aggressive sexual predispositions and social influences, viewing pornography may activate and/or reinforce aggressive tendencies and behaviors [10]. This is referred to as "priming". Those men already at risk for engaging in nonsexual and sexual aggression towards women may have their violent tendencies/preferences/attractions triggered viewing pornography (e.g., because of habituation, arousal to the material, etc.). "Sexually aggressive men... are very likely to have habitual cognitive representations relating the concept of women to both sex and hostility" [10]. As a result, one of the inherent problems for utilizing pornography in sex offender treatment is that it would likely be very difficult if not at times impossible to eliminate or recondition such a habituation that was tied to so many powerfully positive rewards for the offender (e.g., feelings of power, control, orgasm, having undetected sexual and nonsexual violent crimes). Pornography use by individuals with certain predisposing characteristics may warrant increased concern about future violence against women or children. These factors appear to include the above mentioned hostile masculinity, sexual promiscuity, psychopathy, and a history of engaging in sex offense behavior [44].

\section{Utilizing Pornography in Sex Offender Treatment}

I have been approached by probation officers who supervise sexual offenders that a handful of treatment professionals working with sex offenders have begun to incorporate pornography into the treatment program (though to be clear this is more of an anomaly than the norm). Some claiming that soft core pornography (depicting naked bodies but not actual sexual activity or contact) could help sexual offenders redefine or recondition their sexual arousal and sexual interests back to consensual and age appropriate subjects. How does the program or therapist choose which pornography to use? And what about the act or person being depicted is the person smiling and age appropriate to the user? Even in soft-core pornography magazines, numerous pictures of the same individual may involve smiling while others demonstrating less consensual or less happy facial expressions. This presents a concern because then the user, in this case an offender, has to reconcile the facial expressions that are not worthy of or recommended to use for masturbation or fantasies. It is very possible that the offender may regain vivid fantasies and feelings about the use of force, coercion, power and control in their relationships and reoffend.

In fairness, interpreting a facial expression is subjective. As a colleague put it, "interpreting facial expressions is very subjective even more so if the viewer is aroused and likes the sexual action, he may see the expression as experience pleasure or ecstasy - expressions when having an orgasm can look to an unknowing observer as pained but in context it is clearly an expression of serious pleasure. Serious laughter appears to have the same facial expression as serious pain both have tears/crying" (A. Listiak, personal communication, August $28,2015)$. In fairness, I did not conduct a review of literature for how facial expression depicted in pornography impact offender's fantasies or behavior. Even a positive facial expression, for example a child smiling, could be interpreted by the viewer as supporting the sexualization of a child, on the other hand it may impact the user to experience empathy and therefore not sexualize to a significant degree or to choose not to engage in direct sexual behavior with a child. I am raising this issue as another concern warranting further research. 
However, if any type of pornography were to be used to recondition a violent or sexually violent offender's thinking, to restructure fantasies to be healthier, it would seem appropriate to have guidelines in place prior to utilizing any pornographic material as part of any treatment.

I am aware that there are therapists who utilize pornography with clients to help improve problems or deficits related to sexual fantasies, behavior, couples relations, and to help overcome sexual dysfunctions. I am not including the research here for this area but I am aware there is in fact research supporting the use of such procedures. However, the sexual offender presents with predispositions that increase the likelihood for violence (sexual and nonsexual), problematic fantasies, ideas, and coping skills, and some have a history of sexual and other violent offenses, as mentioned in this paper. As such, the sexual offender may or may not benefit from use of pornographic material in treatment unless strict guidelines are in place to reduce the risk for the offender returning to a higher degree of pornography usage and of course, the risk for the sexual offender to have deviant fantasies reignited, which the therapist might not be aware of.

One significant study found that offenders who viewed deviant pornography were more likely to reoffend than those who did not [23]. However, as already mentioned above, some studies have found that even soft-core (non-deviant) pornography use increased violent (including sexually violent) re-offense. Even soft-core pornography often contains child pornography depictions (e.g., Playboy contains pictures of the centerfold as a young child and as a teenager), references about children involved in sex with adults, and many of the models are depicted with non-consenting facial expressions (although I understand this is a subjective interpretation). The risk of utilizing a particular pornographic magazine or web site becomes increasingly more challenging to only find positive, healthy, or consensual images (again a subjective assessment unless of course more extreme content (e.g., children, violence).

Cooper described three basic components of internet use related to child pornography that would appear to apply to all forms of online pornography. These include: 1) Accessibility (24-hour, 7-day-a-week availability);2) affordability (a tremendous amount of pornography is available online for free, including pictures and movies of extreme deviant pornography, including child and rape porn); 3) anonymity (the user can access the online pornography anytime, anywhere, in complete privacy). These three factors make the internet alluring for offenders and it would be nearly impossible to track whether a specific offender was accessing online pornography. Despite restrictions for sexual offenders not to have internet access, it is difficult to enforce that condition. If the offender was reintroduced to pornography in treatment or while on supervision, the offender may have old memories or desires or fetishes triggered that may lead to the decision to seek out more deviant pornography despite treatment or supervision requirements.

\section{Fantasy}

Pornography provides a plethora of opportunity for imagination to run wild. People view pornography and may imagine themselves engaging in contact with the person/s depicted in the material. This in and of itself is not good or bad, healthy or unhealthy. Masturbation is a strong reinforce for the fantasies experienced.

However, if the material involves deviant themes, including but not limited to age inappropriate people, violence, forced or manipulated sexual contact, then the fantasies experienced likely foster and support deviant ideas which may lead to a desire to engage in the deviant and fantasized behavior. Even with soft-core pornography, the images may ignite deviant fantasies for some offenders as mentioned in this paper. For the offender, who already has demonstrated comfortability with sexualized and non-sexualized violence, this could be a potential problem stimulating the offender's previously held beliefs about violence in general, including sexual violence. I would argue that the user of pornography may or may not be aware of the facial expression being unhealthier or blatantly deviant but the user has to justify that the material viewed is appropriate or they would not likely use it! So conditioning and habituation can occur to help reinterpreting deviant to being more comfortably acceptable.

Regardless of the theme of the pornographic material, the viewer may utilize fantasy to imagine interacting with the person/s depicted, which is surreal and not based in reality (e.g., it is not actually happening). With repeated pornography usage, repeated sexual fantasies about the interaction being depicted, and with orgasm as the final reward, what is fantasized becomes acceptable in the viewer's belief system - whether they chose to act it out or try it out is still a choice to be made, but now the situation of re-enactment is possible. Add increased time spent on viewing the pornography, more isolation as a result of the pornography (e.g., not something typically discussed with others, not shared with others unless engaging in online communication with others with similar interests - which tend to provide support in the users mind of the acceptance of the behavior depicted), and the risk increases for the offender to begin to develop or continue to develop deviant fantasies already existing.

\section{Defining Appropriate Themed Pornography for Use in Sex Offender Treatment}

If pornography is to be used in sex offender treatment, I believe that one of the most important issues is that the material depicts age appropriate and fully consensual behavior. Even in reviewing soft core magazines and websites, the facial expressions of the models often vacillate from smiling and pleasant expressions to negative expressions (again, subjective in some instances, while in other circumstances the expressions are clearly non-consenting). Negative expressions include but are not limited to any expression other than smiling or appearance of enjoyment and consent. For example, the models facial expressions often appear to indicate boredom, fear, concern, apprehension and some even appear to be teary. If the goal is to recondition the sexual offender into modifying their sexual interest and arousal to prefer consenting sexual partners, then the facial expressions are everything. It is interesting that in many of the soft core magazines the collection of photos for each model include facial expressions that appear blatantly happy and consensual and move to more negative, nonconsenting expressions (this is likely one way the pornographers introduce more deviant themes to the user). So deciding what photos to use in sex offender treatment is a difficult task, and perhaps there is not even a single magazine or website that has only models displaying consensual facial expressions. You could pick and choose which photos or videos to view, not all commercial pornography depicts negative themes.

However, the more concerning and pressing issue for me is that there is no scientific data, no research to date, to support using pornographic material in sex offender treatment. There are those who opine (again, taken from probation officers supervising sex offenders whose treatment programs are wanting or already using pornography as part of their treatment program) that utilizing pornography in 
Page 5 of 6

treatment is effective and appropriate. However, lets be very clear here. Opinions about including pornographic material as part of sex offender treatment is not supported by the literature at this time and therefore should not be utilized until such research exists to support its effectiveness. The risk of the offender reoffending as a result to being expected to view or use pornography may well be too much for them to handle while running the risk of reigniting deviate interest in pornography.

Understanding that some sex offenders and other violent offenders are already presenting with risk factors for engaging in future violence is imperative. A violent offender is always at risk for engaging in future violence, the only question is to the degree of risk. But many of the risk factors are static, that is, not likely to ever change. Regardless of whether the offender receives and completed treatment, the more serious risk factors will always be present. Again, for some of the child porn consumers and those who are not presenting with higher risk factors mentioned in the paper, they remain at lower risk for either engaging in contact sex offenses or for re-offense post treatment.

If one considered utilizing pornographic material for someone who has not engaged in violence (physical or sexual), then perhaps utilizing pornography in therapy may present with useful and potentially effective changes (though again, research appears lacking to support this). The use of pornographic material may or may not be effective with nonviolent individuals and these individuals do not present with the risk factors associated with physically and sexually violent behavior. The batterer, sexual offender, child sexual abuser, etc., have all moved into higher risk categories given their propensity and choice to engage in sexually deviant, violent, and/or sexually inappropriate behavior. Utilizing pornographic material for these individuals appears not only unsupported at this time by the literature but risky to say the least. Again, many of the child pornography users do not present with high risk factors related to engaging in contact sex offenses.

One last concern would be, if pornography is used as part of the offender's treatment, research has demonstrated that the images, even soft-core, may reignite the offender's memories and beliefs about previously viewed pornography or offenses (cited several times in this paper), especially for the sex offender presenting with already identified risk predispositions. In fairness, some research has not demonstrated this impact, especially for soft-core pornography. How would the offender's pornography use be monitored in the community? The offender could access pornography from almost anywhere, from anyone's computer, any store that sells pornography, as well as from a cell phone. The only way I see addressing this problem is to polygraph the offender several times during treatment to assess whether they have accessed pornography other than what they were allowed to access. I see this as potentially a set-up for the offender who, because of utilizing pornography in treatment, has increased compulsions and fantasies to view pornography, then is on the edge to make a decision to act-out or not (granted it is $100 \%$ their choice to do so or not), but it appears to be a possible temptation that is not warranted in the literature to date.

\section{Summary}

There are numerous studies that have demonstrated the negative effects of pornography use by sexual and nonsexual violent offenders. Pornography has played a role in the development and/or maintenance of deviant violent and/or sexual thoughts leading at times to offense behavior. Directionality has not been proven, regardless of whether for some offenders pornography spurs deviant thinking that leads to violent behavior while for others they engage in deviant and violent behavior and then use pornography, pornography still plays a significant role, especially deviant and violent pornography. Add to this Hostile Masculinity and Sexual Promiscuity, and other psychological and antisocial factors, along with the use of pornography (strongest for deviant pornography) and the combinations leads to more significant re-offense rates. Then again, even soft-core pornography and clothed models may still be arousal fuel for some offenders. In addition, for most child pornography users, they may not crossover to engaging in contact sex offenses. To date there is no research to demonstrate any utility or effectiveness of utilizing pornography in sex offender treatment despite a very small number of providers of sex offender treatment incorporating pornography into the treatment program. The use of pornography in sex offender treatment appears risky at this time for both the treatment program and the offender. More research is needed in this area before pornography is utilized in sex offender treatment [45-48].

Again this paper was written as a response to several probation officers question about incorporating pornography into sex offender treatment. Pornography has been used for those who do not present with predispositions for violence and/or sexual offenses, and done so with effectiveness. There is also feminist and female orientated pornography that depicts intimacy and consent. This paper was not addressing those uses of pornography and in fairness the literature reviewed to date has been very positive. Unfortunately many sex offenders present with predispositions and histories of high risk factors that may or may not preclude their use of pornography at some point in their lives. I want to state clearly that the sex offender treatment programs that spurred this review of literature and paper do not represent $99 \%$ or better of the sex offender treatment providers. However, I wanted to address this issue more thoroughly in hopes to educate about this topic.

Lastly, I have a concern for the limitations of any research, including the research as presented in this paper. The length of time assessed for re-offense is at times far too short. Violent offenders (sexual and nonsexual) remain at risk for re-offense for life. At best they may be assessed as being "low" risk, but they will never be "no" risk. Because circumstance and personal choice impacts any decision to offend or reoffend, re-offense rates may miss a low or high degree of re-offense because the re-offense studies may not have followed the offender 20 or 30 years, but rather 3-6 years.

\section{References}

1. Abel GG (1985) Use of pornography and erotica by sex offenders. Paper presented to the United States Attorney Generals Commission on Pornography, Houston, TX.

2. Allen M, D Alessio D, Brezgel K (1995) A meta-analysis summarizing the effects of pornography II: Aggression after exposure. Human Communication Research 22: 258-283.

3. Bergen RK, Bogle KA (2000) Exploring the connection between pornography and sexual violence. Violence Vict 15: 227-234.

4. Check JVP, Guloien TH (1989) Reported Proclivity for Coercive Sex Following Exposure to Sexually Violent Pornography, Nonviolent Dehumanizing Pornography, and Erotica. In: Zillman D, Bryant J (eds.) Pornography: Research Advances and Policy Considerations. Hillsdale, NJ: Erlbaum.

5. Crossman LL (1995) Date rape and sexual aggression by college males: incidence and the involvement of impulsivity, anger, hostility, psychopathology, peer influence and pornography use (Doctoral 
dissertation, Texas A\&M University). Dissertation Abstract International 55: 4640 .

6. Donnerstein E (1984) Pornography: Its effect on violence against women. In: Malamuth N, Donnerstein E (eds.) Pornography and sexual aggression. New York: Academic Press 53-80.

7. Kingston DA, Malamuth NM, Fedoroff P, Marshall WL (2009) The importance of individual differences in pornography use: theoretical perspectives and implications for treating sexual offenders. J Sex Res 46: 216-232.

8. Hald GM, Malamuth NM, Yuen C (2010) Pornography and attitudes supporting violence against women: revisiting the relationship in nonexperimental studies. Aggress Behav 36: 14-20.

9. Malamuth NM, Addison T, Koss M (2000) Pornography and sexual aggression: are there reliable effects and can we understand them? Annu Rev Sex Res 11: 26-91.

10. Malamuth NM, Hald GM, Koss M (2012) Pornography, individual differences in risk and men's acceptance of violence against women in a representative sample. Sex Roles 66: 427-439.

11. Marshall WL (1988) The use of sexually explicit stimuli by rapists, child molesters, and nonoffenders. The Journal of Sex Research 25: 267-288.

12. Zillmann D, Bryant J (1984) Effects of massive exposure to pornography. In: Malamuth $\mathrm{N}$ and Donnerstein $\mathrm{E}$ (eds.) Pornography and sexual aggression. New York: Academic Press 114-137.

13. Marshall WL, Seidman BT, Barbaree HE (1991) The effects of prior exposure to erotic and nonerotic stimuli on the rape index. Annals of Sex Research 4: 209-220.

14. Boeringer SB (1994) Pornography and sexual aggression: Associations of violent and nonviolent depictions with rape and rape proclivity. Deviant Behavior 15: 289-304.

15. Frank JG (1990) Risk factors for self-reported rape in prisoners and college students (Doctoral dissertation, University of South Carolina). Dissertation Abstracts International 51: 454.

16. Allen PE, Keough VA, Armstrong ML (2013) Creating innovative programs for the future. J Nurs Educ 52: 486-491.

17. McCarthy JA (2010) Internet sexual activity: a comparison between contact and non-contact child pornography offenders. Journal of Sexual Aggression 16: 181-195.

18. Malamuth N, MacIlwraith B (1989) Fantasies and exposure to sexually explicit magazine. Communication Research 15: 753-771.

19. Prentky R, Burgess A, Dowdell EB, Fedoroff P, Malamuth N, et al. (2010) A multi-prong approach to strengthening Internet child safety. Justice Resource Institute, National Center for Missing \& Exploited Children 40.

20. Vega V, Malamuth NM (2007) Predicting sexual aggression: the role of pornography in the context of general and specific risk factors. Aggress Behav 33: 104-117.

21. Williams KM, Cooper BS, Howell TM, Yuille JC, et al. (2009). Inferring sexually deviant behaviour from corresponding fantasies. The role of personality and pornography consumption. Criminal Justice and Behavior 36: 198-222.

22. Vrieze SI, Grove WM (2008) Predicting sex offender recidivism. I. Correcting for item overselection and accuracy overestimation in scale development. II. Sampling error-induced attenuation of predictive validity over base rate information. Law Hum Behav 32: 266-278.

23. Kingston DA, Fedoroff P, Firestone P, Curry S, Bradford JM (2008) Pornography use and sexual aggression: the impact of frequency and type of pornography use on recidivism among sexual offenders. Aggress Behav 34: 341-351.

24. Seto MC, Hanson RK, Babchishin KM (2011) Contact sexual offending by men with online sexual offenses. Sex Abuse 23: 124-145.

25. Aslan D (2011) Critically evaluating typologies of Internet sex offenders: a psychological perspective. Journal of Forensic Psychology Practice 11: 406-431.
26. Quayle E, Taylor M (2002) Child pornography and the Internet: Perpetuating a cycle of abuse. Deviant Behavior 23: 331-361.

27. Seto MC, Wood JM, Babchishin KM, Flynn S (2011) Online Solicitation Offenders Are Different From Child Pornography Offenders and Lower Risk Contact Sexual Offenders. Law and Human Behavior 36: 320-330.

28. Calcetas-Santos O (2001) Child pornography on the Internet. In: Arnaldo CA (ed.) Child Abuse on the Internet: Ending the Silence. New York: Berghahn 57064.

29. Krone T (2004) A typology of online child pornography offending. Trends \& Issues in Crime and Criminal Justice 279.

30. Riegel DL (2004) Effects on boy-attracted pedosexual males of viewing boy erotica. Arch Sex Behav 33: 321-323.

31. Seto MC, Eke AW (2005) The criminal histories and later offending of child pornography offenders. Sex Abuse 17: 201-210.

32. Carter DL, Prentky RA, Knight RA, Vanderveer PL, Boucher RJ (1987) Use of pornography in the criminal and developmental histories of sexual offenders. Journal of Interpersonal Violence 2: 196-211.

33. Neutze J, Grundmann D, Scherner G, Beier KM (2012) Undetected and detected child sexual abuse and child pornography offenders. Int J Law Psychiatry 35: 168-175.

34. Eke AW, Seto MC, Williams J (2011) Examining the criminal history and future offending of child pornography offenders: an extended prospective follow-up study. Law Hum Behav 35: 466-478.

35. Fisher WA, Grenier G (1994) Violent pornography, antiwoman thoughts, and antiwoman acts: In search of reliable effects. The Journal of Sex Research 31: 23-38.

36. Bogaert AF, Woodard U, Hafer CL (1999) Intellectual ability and reactions to pornography. The Journal of Sex Research 36: 283-291.

37. Malamuth NM, Briere J (1986) Sexual violence in the media: Indirect effects on aggression against women. Journal of Social Issues 42: 75-92.

38. Malamuth NM, Check JV (1983) Sexual arousal to rape depictions: individual differences. J Abnorm Psychol 92: 55-67.

39. Malamuth NM, Check J (1985) The effects of aggressive-pornography on beliefs in rape myths: Individual differences. Journal of Research in Personality 19: 299-320.

40. Bandura A (1977) Social learning theory. Englewood Cliffs, NJ: PrenticeHall.

41. Malamuth NM, Linz D, Heavey CL, Barnes G, Acker M (1995) Using the confluence model of sexual aggression to predict men's conflict with women: a 10-year follow-up study. J Pers Soc Psychol 69: 353-369.

42. Malamuth NM (1998) The conuence model as an organizing framework for research on sexually aggressive men: Risk moderators, imagined aggression, and pornography consumption. In: Geen RG, Donnerstein E (eds.) Human Aggression: Theories, Research, and Implications for Social Policy, San Diego: CA: Academic Press 229-245.

43. Malamuth NM (2003) Criminal and noncriminal sexual aggressors: Integrating psychopathy in a hierarchical-mediational conuence model. In: Prentky RA, Janus ES, Seto MC (eds.) Sexually Coercive Behavior: Understanding and Management, New York, NY: Annals of the New York Academy of Sciences 33-58.

44. Fisher WA, Kohut T, Di Gioacchino LA, Fedoroff P (2013) Pornography, sex crime, and paraphilia. Curr Psychiatry Rep 15: 362.

45. Cooper A (1998) Sexuality and the Internet: Surfing into the new millennium. CyberPsychology and Behavior 1: 187-193.

46. Lanning KV (2001) Child molesters: A behavioral analysis.

47. Marshall WL (2000) Revisiting the use of pornography by sexual offenders: Implications for theory and practice. Journal of Sex Aggression 6: 67-77.

48. Webb L, Craissati J, Keen S (2007) Characteristics of internet child pornography offenders: a comparison with child molesters. Sex Abuse 19: $449-465$. 